\title{
Oncology care during COVID-19 pandemic in a low middle-income country
}

\author{
Amita Trehan ${ }^{1}$, Richa Jain ${ }^{2}$, and Deepak Bansal ${ }^{3}$ \\ ${ }^{1}$ Post Graduate Institute of Medical Education and Research \\ ${ }^{2}$ Postgraduate Institute of Medical Education \& Research \\ ${ }^{3}$ Advanced Pediatric Center, Postgraduate Institute of Medical Education and Research
}

May 11, 2020

\begin{abstract}
The 2019 novel coronavirus disease (COVID-19) has affected all aspects of life globally and care of children with malignancies is no exception. We are part of a large tertiary care 2000 bedded university hospital in North India. Approximately 450 new malignancies are diagnosed annually, translating to 10 patients per week. About 200 children attend the clinics every week. Additionally, 15-20 walk-in patients are evaluated daily in the daycare. Patients travel from distances as far as $500 \mathrm{~km}$ to reach our center. Merely $20 \%$ live within $50 \mathrm{~km}$ of the hospital, and approximately $35 \%$ reside at a distance exceeding $200 \mathrm{~km}$. Two-third of the patients hail from urban areas and one third belong to rural areas. The majority of families stay in a patient hostel in the hospital premises, and a few rent a flat in the city for the 4-9 months duration of intensive phase of therapy. The Government of India mandated a lockdown on the 24th March 2020 in response to the coronavirus pandemic and the outpatient services of the hospital were closed. The borders with the neighboring states were sealed \& vehicular movement curtailed with barring of public transport \& suspension of all interstate and intercity travel. The citizens were advised to maintain social distancing. The unit was faced with the formidable challenge of ensuring the well-being of children under our care from a wide geographical spread with minimal access to Pediatric Oncology services in their hometowns. How did we manage our patients?
\end{abstract}

\section{Hosted file}

Oncology care in a pandemic.9.5.20.doc available at https://authorea.com/users/319916/ articles/449592-oncology-care-during-covid-19-pandemic-in-a-low-middle-income-country 